\title{
ENSINO DO ESPANHOL NO BRASIL: O CASO DAS VARIEDADES LINGÜÍSTICAS
}

\author{
Bruno Rafael Costa Venâncio da Silva \\ billnoriega@hotmail.com \\ Tatiana Maranhão de Castedo \\ Professora do CEFET RN/ Zona Norte \\ tatimaranhao@hotmail.com
}

\begin{abstract}
RESUMO
Este artigo tem a intenção de proporcionar uma visão geral do ensino das variedades linguiísticas da língua espanhola no Brasil através de estudos realizados sobre as representações que as línguas trazem aos seus "aprendentes" em relação ao prestígio e a credibilidade que cada região falante da língua espanhola impõe às instituições de ensino médio e superior no momento de eleger uma variedade lingüística, os materiais didáticos utilizados em nosso país e os fatores econômicos que envolvem seu ensino. Além dessa visão geral sobre os problemas que permeiam o ensino de espanhol em nosso país, mostrar-se-á as variedades mais recorrentes da língua espanhola através de atividades e explicações teóricas das variantes trazidas pelos livros didáticos com o intuito de desmistificar a idéia já fossilizada nos alunos, tanto de ensino médio, superior e de cursos de idiomas, os mitos existentes em relação ao aprendizado de variedades latinoamericanas, em especial a falada pelo bloco rio-platense (Argentina. Paraguai e Uruguai).
\end{abstract}

Palavras-chave: Variedades Lingüísticas, Ensino de Espanhol e Espanhol no Brasil.

\section{ENSEÑANZA DEL ESPAÑOL EN BRASIL: EL CASO DE LAS VARIEDADES LINGÜÍSTICAS}

\section{RESUMEN}

Este artículo tiene la intención de proporcionar una visión general de la enseñanza de las variedades linguísticas de la lengua española en brasil a través de estudios realizados sobre las representaciones que las lenguas traen a sus "aprendientes" en relación al prestigio y a la credibilidad que cada región hablante de la lengua española impone a las instituciones de enseñanza secundaria y superior en el momento de elegir una variedad lingüística, los materiales didácticos utililzados en nuestro país y de factores económicos que involucrados en su enseñanza. además de esa visión general sobre los problemas que rodean la enseñanza del español en nuestro país, se considera importante revelar las variedades más recurrentes de la lengua española a través de actividades y explicaciones teóricas de las variantes ofrecidas por los libros didácticos con el objeto de romper con la idea ya fosilizada en los alumnos, de enseñanza secundaria, superior y de cursos de idiomas, los mitos existentes en relación al aprendizaje de variedades latinoamericanas, en especial, la hablada por el bloque rioplatense (Argentina. Paraguay y Uruguay).

Palabras-clave: Variedades Lingüísticas, Enseñanza de Español y Español en Brasil. 


\section{ENSINO DO ESPANHOL NO BRASIL: O CASO DAS VARIEDADES LINGÜÍSTICAS ${ }^{1}$}

\section{INTRODUÇÃO}

O acordo assinado entre os países do MERCOSUL, em 1991, ocasionou um boom nos cursos de castelhano em nosso país. Desde então, o idioma de Cervantes está em evidência e tende a evoluir ainda mais. A Lei $\mathrm{n}^{\circ} 11.161$ de 5 de agosto de 2005 é responsável pela segunda fase de crescimento do ensino da língua espanhola no Brasil, já que impõe em seus 7 artigos a obrigatoriedade das escolas públicas e privadas a ofertar aos seus alunos o ensino da língua em questão. Porém, em nenhum momento a lei propõe discutir qual variedade da língua espanhola deve ser ensinada. Não se destaca uma como sendo mais relevante e, consequentemente, a que deva ser contemplada na nossa educação, deixando a critério do professor a escolha do material didático a ser utilizado, bem como a variedade lingüística mais enfocada na sala de aula.

Com a falta de profissionais especializados nessa área de conhecimento por se tratar de uma novidade curricular, o governo brasileiro encontrou como solução para atender a essa demanda de alunos a abertura de cursos superiores para formação de professores de espanhol e especializações para os docentes efetivos da rede pública, que devem concretizar tal exigência até agosto de 2010, ano em que a mão de obra deverá estar mais qualificada.

Deve-se levar em conta que uma língua falada por mais de 350 milhões de habitantes distribuídos em 21 países (MORENO FERNÁNDEZ, 2000), tem a tendência natural de sofrer variações lingüísticas. Esta riqueza de diversidade não é levada em consideração no ensino em muitas instituições do nosso país por questões como a mera imposição da variedade peninsular, talvez por ter sido detentora da origem desta língua, além da sua condição de língua dos colonizadores da América, talvez pelo escasso conhecimento da dialetologia por parte do professores ou ainda pela predominância de materiais didáticos editados na Espanha. Inclusive, os cursos superiores em nosso país, embora tenham a autonomia para desenvolver sua estrutura curricular, muitos deles sequer oferecem a disciplina de Dialetologia, como é o caso da Universidade Federal da Paraíba e da Universidade Estadual do Rio Grande do Norte, na qual percebe-se uma limitação da variedade lingüística aplicada na sala de aula. $\mathrm{O}$ nosso artigo tem como objetivo oferecer um panorama desses problemas citados através de trabalhos realizados por Irala (2004), Conceição Pinto e Silva (2005), Conceição Pinto (2006), Venâncio da Silva e Alves (2007), Venâncio da Silva, Alves da Silva e Ribeiro (2007) e Bugel e Santos (a sair) com o propósito de incentivar o ensino das variedades lingüísticas da língua espanhola em todos os setores da educação brasileira com o intuito, até mesmo esclarecedor, no momento de responder a questionamentos feitos pelos alunos como os que seguem: professor, vou aprender o espanhol de qual país? Se eu aprender a variação da Argentina, poderei comunicar-me com facilidade com um espanhol ou mexicano? O espanhol falado no Chile é o mesmo falado na Costa Rica?

Há de deixar muito claro na cabeça dos alunos que, apesar da heterogeneidade da língua, ela apresenta um fundo comum, homogêneo que permite a comunicação entre todos os hispânicos. A estrutura da língua é exatamente a mesma e, apesar da consciência da

\footnotetext{
${ }^{1}$ Agradeço aos meus colegas de luta pelo respeito à diversidade lingüística nas aulas de espanhol no Brasil Carlos Felipe Pinto (UNICAMP) e Edmilson Correia (UFPE).
} 
existência de variedades ocasionadas por fatores como a sua distribuição geográfica, elas são minoria em relação a unidade oferecida pela língua.

\section{IMPOSIÇÃO DE VARIEDADE LINGÜÍSTICA E DIALETOLOGIA}

Irala (2004) realizou uma entrevista com professores e alunos do curso de Letras com habilitação em Língua Espanhola de uma cidade na fronteira do Rio Grande do Sul com o Uruguai. Como resultado de suas crenças sobre ensino de variedades lingüísticas nas aulas de espanhol, ela encontrou alguns exemplos que mostram equívocos em relação à qual variedade e porque deveria ser a ministrada pelo professor. Alguns dos entrevistados responderam da seguinte maneira:

1) Espanhol da Espanha, porque é uma língua melhor de ser trabalhada com o aluno.

2) Prefiro o Espanhol da Espanha. acho mais claro e muito mais bonito.

3) Da Espanha, porque é mais clássico.

4) Prefiro o Espanhol da Espanha, porque é o mais puro, pois é a línguamãe. O Espanhol da América já teve muitas influências de outros povos e costumes.

5) Da Espanha, porque além de ter aprendido assim, penso que é mais sonoro. (Irala, 2004: 109-110)

Esses resultados são provas claras de pouco ou nenhum conhecimento de dialetologia da língua espanhola por parte dos alunos de letras e professores. Conceitos como melhor ou puro devem ser desmistificados não somente entre futuros professores de espanhol dentro da graduação como alunos que queiram aprender a língua nos cursos de idiomas, escolas de ensino fundamental e médio e na extensão universitária.

Como exemplo de imposição da variedade dentro do universo de formação de professores de espanhol, temos o exemplo da Universidade Estadual do Rio Grande do Norte, na qual o estudo realizado por Venâncio da Silva, Alves da Silva e Ribeiro (2007) mostra que a maioria dos alunos optou pela variedade castelhana porque era a adotada pelo corpo docente da instituição, como a justificativa dada pelo aluno A01 - UERN a seguir: Não sei, talvez por ser mais falada na instituição que eu estudo (VENÂNCIO DA SILVA, ALVES DA SILVA E RIBEIRO, 2007: p. 8)

No momento de buscar um protótipo da língua a ser utilizada no ensino do espanhol, podemos recorrer a dois parâmetros principais: o geográfico e o social. O primeiro nos leva a olhar a determinados lugares, enquanto que o segundo nos conduz a grupos sociolingüísticos concretos.

No ensino, costuma-se dirigir três possibilidades prototípicas: o modelo do espanhol de um só lugar (Castilha); o modelo do espanhol de cada zona específica e o modelo dos usos panispânicos. Alguns professores dão preferência ao modelo castelhano por acreditar que é o que ainda tem maior prestígio e por oferecer a vantagem de concordar com a norma acadêmica (mito já abolido, tendo em vista a participação efetiva da Associação de Academias de Língua Espanhola na definição das normas deste idioma). Também há aqueles que trabalham com um modelo concreto do espanhol americano. 
Andrés Bello, quem tinha se posicionado pela autoridade castelhana para preservar a unidade da língua, chegou a afirmar: "No se crea que recomendando la conservación del castellano sea mi ánimo tachar de vicioso y espurio todo lo que es peculiar de los americanos" (MORENO FERNANDEZ, 2000: p. 80).

Desde tal perspectiva, existe a possibilidade de tomar como modelo o espanhol da Espanha, o da região mais próxima ou aquele que se tem mais afinidade e relação.

O uso da língua culta neutraliza a fragmentação porque os usos cultos de muitas áreas hispânicas se aproximam ao "protótipo castelhano", inclusive com suas particularidades, ou seja, usar a língua culta significa aproximar-se à norma. Consequentemente, a norma é única aos falantes do espanhol, o que comprova que esta variedade permite a homogeneidade do idioma e a criação de uma lengua general acessível a todos.

Lhote (1995) diz que aceitar a variabilidade dentro de uma mesma língua é ser um ouvinte atento. Entendemos que os docentes muitas vezes não conhecem todas as variedades da língua espanhola, porém, deveriam ensinar as mais recorrentes (as usadas em uma maior extensão territorial e/ou de maior importância para a região do aluno) e incentivar ao aluno a buscar informações sobre elas. A proposta lançada por Conceição Pinto (2006) sobre as zonas de contato direto e indireto para o ensino de variedades da língua espanhola nos parece de grande relevância para nosso país, já que temos muitas regiões que possuem fronteiras com países hispanohablantes. No que se refere às zonas de contato direto, propõe-se que o professor ensine a variedade que os alunos vão ter mais contato, ou seja, professores de cidades na fronteira do Rio Grande do Sul com Uruguai, deveriam adotar a variedade rio-platense. Já as zonas de contato indireto, ou seja, aquelas que não possuem fronteiras com países de língua espanhola, os professores devem adotar a sua própria variedade, mas sem esquecer de revelar variedades diferentes da utilizada para que estes optem pela que possui mais interesse ou para que simplesmente conheça outros horizontes da língua estudada. Temos que considerar que os interesses dos alunos pela aprendizagem da língua podem ser os mais diversos (uma viagem à Argentina, bolsa de estudos na Espanha, negócios, trabalho, etc...). O professor pode e deve utilizar sua variedade lingüística, mas deve evitar limitar o universo dos alunos em relação a uma possível escolha da variedade a ser usada e muito menos questionar a vontade e as necessidades deles, pois não há sequer uma delas que tenha maior prestígio que outra.

\section{MATERIAIS DIDÁTICOS}

A imposição de variedades lingüísticas não se dá somente através do corpo docente, senão também da publicação de livros da área no nosso país. Poucos livros trabalham a diversidade da língua espanhola como o Puentes (2000) da editora SBS. Além de trazer diálogos com falantes do espanhol de vários países, o material propõe atividades para que o aluno possa contrastar as variedades, como a utilização do pronome de tratamento informal vos, uma marca bastante forte do espanhol rio-platense, em especial da Argentina. $\mathrm{Na}$ Costa Rica, bem como em muitos outros países latino-americanos também se faz uso deste pronome de tratamento. Abaixo segue um exemplo de atividade sobre este tema, que mais adiante, será vista a maneira como este elemento lingüístico (vos) está sendo abordado nos livros didáticos de espanhol no nosso país através de um estudo realizado com a intenção de checar seu enfoque quantitativa e qualitativamente. 


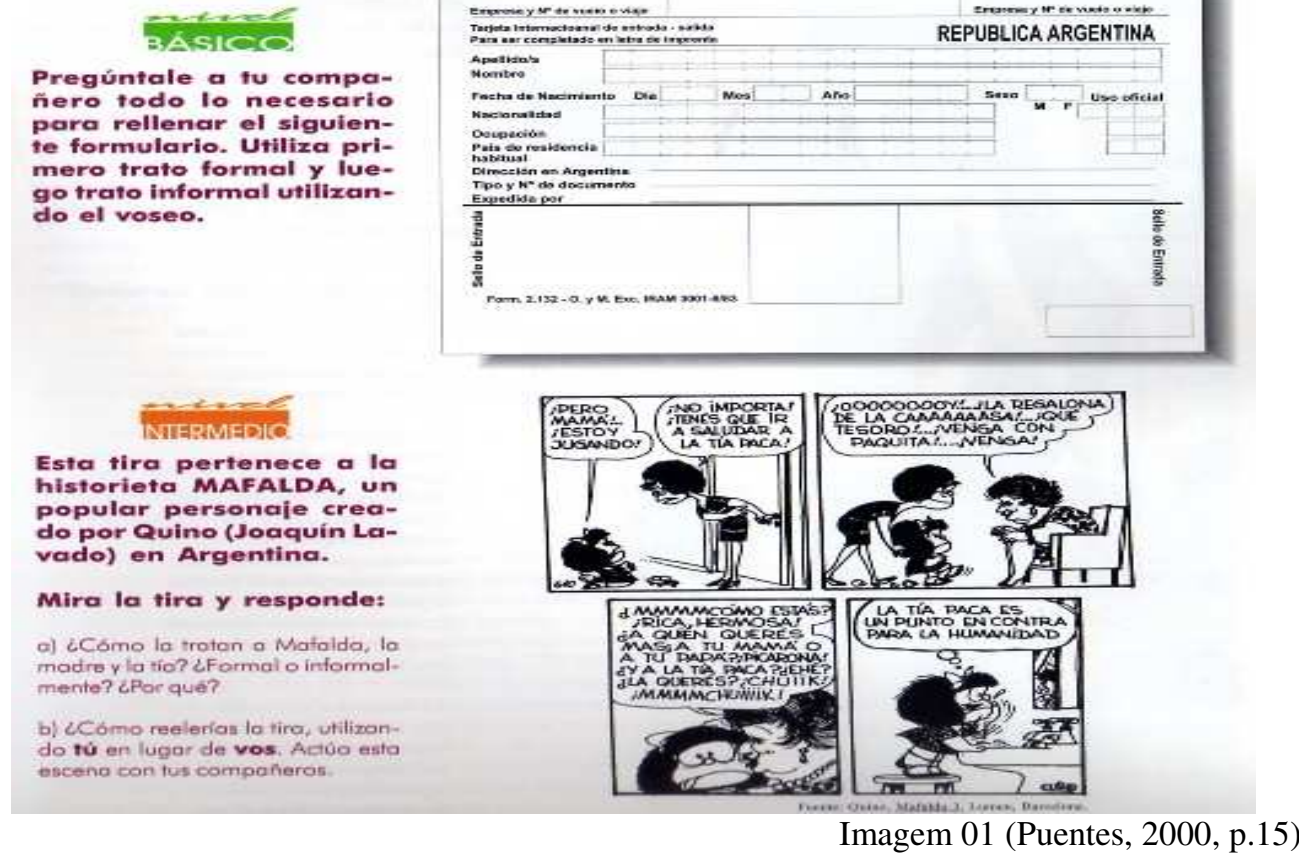

No caso destas duas atividades, o aluno saberá tanto conduzir um diálogo com os pronomes de tratamento informais tú e vos, como aprenderá a utilizar o pronome de tratamento formal usted, além, é claro, de entender em que regiões e em que contextos são utilizados cada um deles. Infelizmente nem todos os livros contemplam essa tendência a nivelar variedades linguiísticas da língua espanhola, ou seja, de trazer à tona uma forma que torna-se maioria pela quantidade de uso, mas que, muitas vezes, é ignorada pelos materiais didáticos. Uma prova disso foi uma pesquisa recente realizada por Venâncio da Silva e Alves da Silva (2007) na qual utilizam em seu corpus livros didáticos de espanhol utilizados no Brasil para descobrir quantos livros abordam o vos e como o expõem para os alunos. Os resultados não foram os mais positivos já que mais da metade dos livros, ou seja, 52,3\% dos mesmos não fazem sequer referência a este pronome de tratamento. Somente 4,76\% dos livros, além de o abordarem, propõem atividades e apresentam suas conjugações. O livro Español para Brasileños (1997) da editora FTD cita a existência do vos, porém o trata como regionalismo, como podemos ver abaixo:

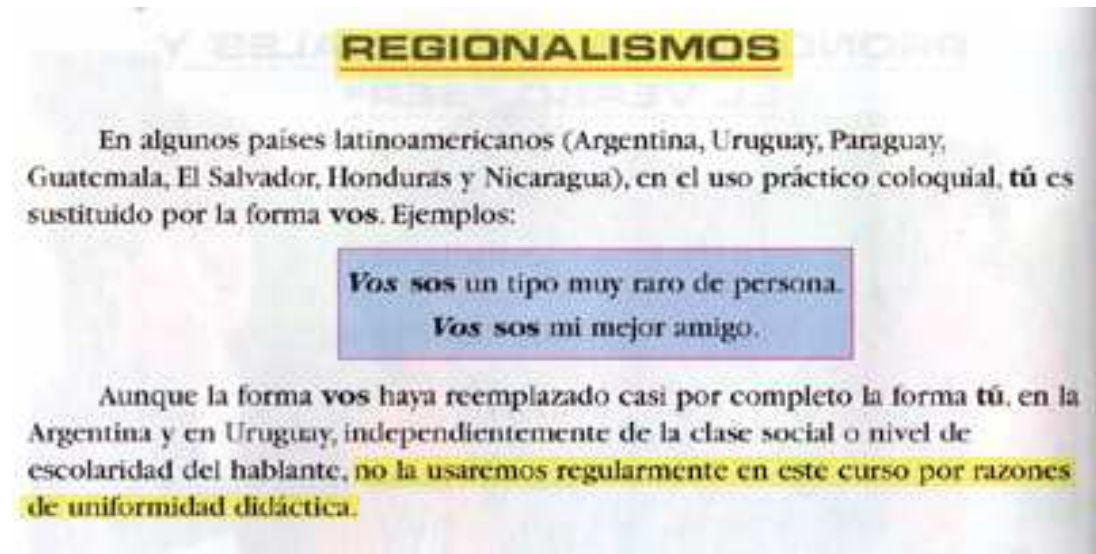

Imagem 02 (Español para Brasileños, 1997, p. 16)

Este pronome de tratamento é utilizado na Argentina, Uruguai, Paraguai, Costa Rica, Honduras, El Salvador, Nicarágua e Guatemala, nas minorias significativas do Chile, 
Bolívia, Colômbia, Venezuela, Peru e México (Cf. LIPSKI, 1994). Então, como pode ser considerado regionalismo um elemento lingüístico utilizado por tantos países? O pronome de tratamento vosotros da variedade castelhana é ensinado praticamente em todos os livros didáticos, e é um elemento minoritário, quase que exclusivo da Espanha, e que nem sequer é difundido em todas as suas regiões. Acreditamos que as variantes americanas não deveriam mais ocupar os tópicos de curiosidade ou simplesmente notas de rodapé dos livros de espanhol, e passem a fazer parte do ensino formal, no mesmo patamar da variante peninsular.

\title{
PRESTÍGIO LINGÜÍSTICO
}

De todas as variedades da língua espanhola, a falada na Espanha é sem dúvida a que possui maior prestígio no ensino de espanhol no Brasil. Além de ter sido o berço desta língua, fator que incentiva às pessoas a estudá-la por acreditar em uma suposta "pureza" da variedade, passa também pelo imaginário dos brasileiros, o valor das coisas que são trazidas da Europa, ou seja o "eurocentrismo". Nos estudos de representação de língua, podemos perceber que o espanhol da Espanha possui maior aceitação e o da Argentina menor credibilidade. Bugel e Santos (a sair) fizeram uma pesquisa com estudantes de espanhol através de questionários com a finalidade de descobrir qual variedade inspira mais confiança entre os alunos e os motivos para essa escolha. Em seu corpus elas encontraram as seguintes respostas:

\begin{abstract}
"Espanhol puro", "espanhol mais claro, correto de se falar", "Porque eles [os espanhóis] são os verdadeiros criadores da língua, já nos outros países colonizados a pronúncia está misturada com outras línguas e acaba sendo um espanhol diferente, "berço da língua", "origem da língua", "espanhol 'original", "melhor lugar para aprender a língua" e "para me livrar do argentino", "pra começar do começo", "saber o espanhol sem interferências", "por ser o país onde o espanhol (Castilla) se originou", "me dá a impressão de ser o espanhol 'padrão', mesmo sabendo da riqueza das variações", "acho mais bonito o sotaque europeu". (BUGEL \& SANTOS, a salir, p.15)
\end{abstract}

Questões relacionadas à "pureza" e origem do espanhol são as que mais aparecem em seus recortes, o que nos confirma o grande prestígio da variedade castelhana frente às outras variedades, especialmente a rio-platense, (no BRASIL).

Há um espanhol mais puro? Se nos propusermos a responder esta pergunta, com certeza, a resposta imediata será "não". A verdade é que não há uma variedade da língua espanhola que seja mais pura que outra, mas para melhor entender, faz-se necessário esclarecer o que vem a ser prestígio para poder compreender porque a variação peninsular está longe de ser mais puro que os demais. Alvar assim define prestígio:

\footnotetext{
"Prestigio es la aceptación de un tipo de conducta considerado mejor que otro. Lingüísticamente hablando, es lo que se trata de buscar para elevar la consideración de una modalidad lingüística".
} 


\section{ECONOMIA E ENSINO DE VARIEDADES}

O primeiro impulso do ensino da língua espanhola no Brasil com o advento do MERCOSUL surgiu em 1991. Com o acordo firmado entre Brasil, Argentina, Uruguai e Paraguai para a abertura do MERCOSUL, o ensino da língua espanhola teve sua primeira grande procura. A partir deste fato, seria lógica a dominação da variedade rio-platense em nossas instituições de ensino. Porém, outra variedade entrou em jogo: a castelhana. Em 2000, Espanha não era apenas companheira de negócios, senão uma investidora ativa no Brasil (perdendo apenas para os Estados Unidos) e grande responsável pela difusão da língua espanhola pelo Instituto Cervantes, o centro cultural financiado pelo governo espanhol que promove cursos de língua, cultura e literatura espanhola, como a Aliança Francesa (França), Cultura Inglesa (Inglaterra), Instituto Goethe (Alemanha) e outros cursos de idiomas oficiais de cada país. Segundo Bugel e Santos (a sair):

Quanto à participação da Espanha no mercado brasileiro, pesquisas do CERIS $^{2}$, em 2004, apontam o Brasil como segundo país na América Latina que mais faz negócios com a Espanha. Alguns exemplos incluem a Telefónica, com o maior mercado do país na área: 12.5 milhões de clientes em 2003; a Telefónica Móviles e a Portugal Telecom unidas na Vivo, que opera com telefonia celular em 19 dos 26 estados brasileiros; o Banco Santander Central Hispano, $3^{\circ}$ maior grupo financeiro privado no Brasil, com mais de 3,9 milhões de clientes no país. (BUGEL E SANTOS, a salir, p.2)

Dentro do universo da economia podemos perceber que existe uma preferência pela difusão das variedades castelhana e rio-platense (especialmente de origem peninsular). A primeira como ferramenta de estímulo para ampliação de investimentos espanhóis e a segunda como uma ferramenta para aumentar acordos comerciais com aliados. Com a entrada da Venezuela ao MERCOSUL em 2006, a variedade caribenha pode se tornar também uma outra grande ferramenta para progresso econômico entre nossos países.

\section{CONSIDERAÇÕES FINAIS}

Ao longo deste artigo vimos resultados de várias pesquisas no que diz respeito à forma como as variedades da língua espanhola estão sendo ensinadas (ou melhor, como não estão sendo ensinadas) para alunos brasileiros de espanhol como língua estrangeira, tanto em cursos regulares de idiomas e em escolas públicas e particulares, como também nos cursos de formação para professores de língua espanhola. As características, pelo menos das regiões de maior destaque devem ser exploradas dentro da sala de aula através de aulas expositivas, recursos áudios-visuais ou até mesmo em aulas de conversação ou palestras (gravações) com nativos de diferentes regiões para que os alunos possam sentir suas peculiaridades. Não basta apenas incluí-las em sala de aula senão também desfazer mitos sobre "pureza" ou "melhor falado", já que não há variedade mais pura, como já visto. A língua falada na Espanha também sofreu modificações ao longo dos séculos e palavras de outros idiomas também foram incorporadas ao espanhol (inglês, francês, etc...) como aconteceu na América Latina com esses idiomas e também com dialetos indígenas.

\footnotetext{
${ }^{2}$ CERIS (Centro de Estatística Religiosa e Investigações Sociais): http://www.ceris.org.br/rse/
} 
Estimular a autonomia do aluno em relação a sua própria aprendizagem de variedades da língua espanhola através da Internet (texto, vídeo, música, chat, fórum, etc..) é mais um recurso positivo para que ele possa escolher a variedade que mais lhe agrade ou que tenha mais necessidade de uso. Além do objetivo de estimular a inclusão das variedades linguísticas da língua espanhola em nosso país, também acreditamos que os professores do Brasil de $\mathrm{E} / \mathrm{LE}^{3}$ (e de outros países falantes ou não da língua espanhola), devem buscar se informar e não limitar-se à sua variedade nem a utilizada majoritariamente pela instituição que aprenderam ou do país de origem. Com isso, não queremos que os professores percam suas variedades iniciais, mas que seja respeitada a multidiversidade da língua espanhola em nosso país.

\section{REFERÊNCIAS}

BUGEL, Tália e SANTOS, H. S. (a sair), As atitudes e representações do espanhol no Brasil e a expansão das indústrias da língua no país. In.: CONCEIÇÃO PINTO, Carlos Felipe da; IRALA, Valesca Brasil (eds.), Um dossiê de estudos lingüísticos hispânicos.

CONCEIÇÃO PINTO, Carlos Felipe da (2006). Los brasileños en Brasil: ¿qué español deben aprender?. In.: Actas Del III Simposio Internacional De Didáctica Del Español Para Extranjeros “José Carlos Lisboa”. Rio de Janeiro: Instituto Cervantes, p. 135-147.

IRALA, Valesca B., 2004, “A opção da variedade de Espanhol por professores em serviço e préserviço”, Linguagem \& ensino. v7. n II: 99-120.

LHOTE, E. (1995). Enseigner l'oral en interaction. Paris : Hachette

LIPSKI, John M. (1994) El español de América, Madrid, Ediciones Cátedra S.A.

MORENO FERNÁNDEZ, Francisco. 2000, Qué español enseñar. Madrid: Arco/Libros,

VENANCIO DA SILVA, B. R. C. e ALVES DA SILVA, R. (2007), El voseo en los libros didácticos de $\mathrm{E} / \mathrm{LE}$ en Brasil. Boletín de la Asociación Argentina de Docentes de Español. N 25 noviembre-diciembre 2007. http://www.espanol.org.ar [Consulta: 28 de abril de 2008].

VENANCIO DA SILVA, B.R.C., ALVES DA SILVA, R., RIBEIRO, C.G.A., 2007, "O perfil dos alunos dos cursos de formação superior no ensino de língua espanhola do Rio Grande do Norte", Revista Holos. ano 23 vol 2: 64-71.

\footnotetext{
${ }^{3}$ Español como lengua extranjera.
} 